\title{
Proteins and Peptides at the Interfaces of Nanostructures
}

\author{
ADRIANNE M.M. BRITO ${ }^{1}$, ELISANGELA BELLETI ${ }^{1}$, LUCIVALDO R. MENEZES ${ }^{1}$, \\ ALEXANDRE J.C. LANFREDI ${ }^{2}$ and ISELI L. NANTES-CARDOSO ${ }^{1}$ \\ ${ }^{1}$ Laboratory of Nanostructures for Biology and Advanced Materials - NanoBioMAv, Center of Natural Sciences and \\ Humanities, Federal University of ABC, Av. dos Estados, 5001, Bangu, 09210-580 Santo André, SP, Brazil \\ ${ }^{2}$ Laboratory of Advanced Materials, Center of Engineering and Applied Social Sciences, Federal \\ University of ABC, Av. dos Estados, 5001, Bangu, 09210-580 Santo André, SP, Brazil
}

Manuscript received on November 29, 2018; accepted for publication on February 5, 2019

\begin{abstract}
How to cite: BRITO AMM, BELLETI E, MENEZES LR, LANFREDI AJC AND NANTES-CARDOSO IL. 2019. Proteins and Peptides at the Interfaces of Nanostructures. An Acad Bras Cienc 91: e20181236. DOI 10.1590/00013765201920181236 .
\end{abstract}

\begin{abstract}
The present review focuses on the proteins and peptides at the interfaces of nanostructured metals and semiconductors as a result of their use in synthesis in-situ and functionalization of nanostructures. We start the review with an introduction about the peculiar properties of nanostructured materials and their applications. In the following, the chemical and structural properties of peptides and proteins that allow their use as reducing, stabilizing, and functionalization agents are discussed. Proteins and peptides have not only the chemical groups for the metal ion reducing but also provide templates for directing the crystalline growing of nanostructures to the desired shapes and sizes. Proteins and peptides are also used mainly for the stabilization and functionalization of a diversity of nanostructured materials providing properties such as biocompatibility, plasmon-enhanced catalysis, sensing, micro/nanomotors, spin filters, and others. Nanostructured materials of metal oxides have mainly been functionalized with proteins and peptides to gain specific properties such as light harvesting and spin filters. Herein, we described the synthesis and functionalization of some types of nanostructured materials by using peptides and proteins. In the last part of the review, it is discussed the perspectives and challenges for the use of proteins and peptides in Nanotechnology.
\end{abstract}

Key words: controlled synthesis, noble-metals, nanomaterials, catalysis, proteins, peptides.

\section{INTRODUCTION}

\section{NANOSTRUCTURED MATERIALS}

The physical and chemical properties of the solids are dependent on the following parameters: chemical composition, atomic structure and the solid size in one, two and three dimensions.

Correspondence to: Iseli L. Nantes-Cardoso

E-mail: ilnantes@ufabc.edu.br/

ilnantes@gmail.com

ORCid: https://orcid.org/0000-0003-1434-3154
Considering the latter parameter, the study of the nanostructured materials has gained enormous interest because they can provide advances in theragnosis, cosmetics, sensing, energy harvesting, conversion and storage, information storage, chemical, and photocatalysis, among others (Roduner 2006, Seehra 2017, Logothetidis 2012, Eustis et al. 2005, Huang et al. 2007, Rhyner et al. 2006, Parameswaran and Tian 2018, Geonmonond et al. 2018). To be considered nanocrystals, the crystals must have at least one dimension in the 
scale of 1 to $100 \mathrm{~nm}$. Therefore, size matters for the material properties and there are two types of size-dependent effects: surface and quantum confinement effects (Roduner 2006, Gleiter, 2000). The surface effect is related to the fraction of total atoms $(N)$ at the surface that is defined as dispersion $\mathrm{F}$. The dispersion $\mathrm{F}$ increases proportionally with the inverse radius or diameter, i.e., with $N^{-1 / 3}$. The relation of $\mathrm{F}$ with $N^{-1 / 3}$ is also maintained for long cylinders of radius $r$ and thin plates of thickness $d$ (Roduner 2006). An example of the relationship of dispersion with the cluster size is showed in Figure 1. In the clusters, the atoms at the surface are poorly coordinated, and consequently, they have lower stabilization. These atoms exhibit the higher affinity for adsorbent molecules. The lower stabilization of the surface atoms also responds to the lower melting points of the superficial layer of the clusters. Surface effects are also related to the breakdown of thermodynamics in nanocrystals. The behavior of nanocrystals resembles more those of molecules than bulk matter. Therefore, at a given temperature, different phases are present at different positions and, in this condition, the Gibbs phase rule becomes meaningless.

Another characteristic of the nanoscale materials is the quantum confinement (Roduner 2006, Rao et al. 2004a). Distant atoms have their valence atomic orbitals with the same energy. In a bulk solid, the proximity of the atoms leads to the orbital overlap which, except for noble gases, promotes the orbital combination to extended band structures. In a solid with $N$ atoms in proximity, the Pauli Exclusion Principle determines the splitting of each valence atomic orbital into $N$ molecular orbitals. In a band, the density of states (DOS) is on the order of $N / \mathrm{eV}$. The bandwidth (a few eV) increases only slightly with the addition of more atoms making DOS basically proportional to $N$ and consequently very large for bulk materials and low for nanostructures. The electrons that are confined to the extent of a solid, of the order of meters, are nearly free, i.e., they can move almost freely

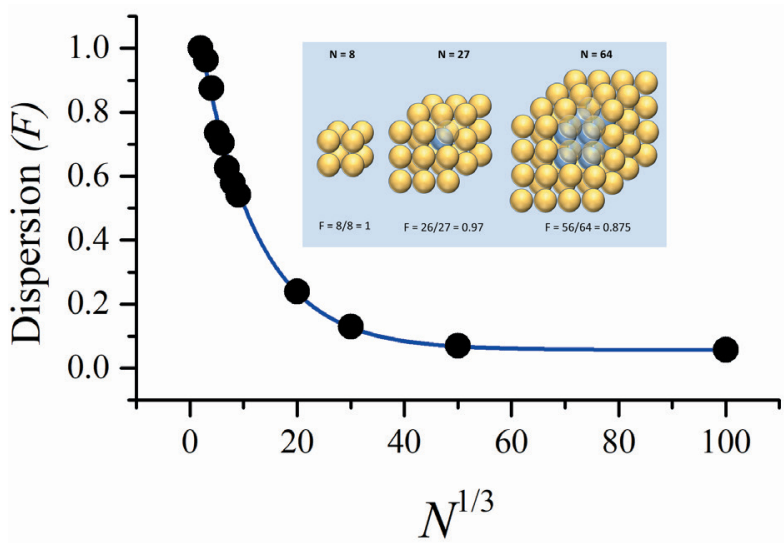

Figure 1 - Dispersion F plotted as a function of $N^{1 / 3}$ for $N$ up to $10^{6}\left(N^{1 / 3}=100\right)$. The inset shows the structure of the first three cubic clusters. The surface atoms are represented in yellow, and the bulk atoms are represented in blue. Some surface atoms were made $50 \%$ transparent to allow the visualization of the blue atoms inside the cluster. The figure was adapted from ref. Roduner 2006.

through the crystal lattice. Electrons confined to the vicinity of individual ionic cores are named bound electrons. The quantum mechanical approach to handling the effect of confinement is consistent with the results obtained from the use of the analogy of waves on a string (Roduner 2006, Rodary et al. 2007). Considering the wave-particle duality, let us consider electron as a wave and relate energy, momentum, and wave vector corresponding to this particle through equation 1 :

$$
E=\frac{\hbar^{2} k^{2}}{2 m}(1)
$$

Where, $\hbar=\frac{h}{2 \pi}$ and the wave vector $k=\frac{2 \pi}{\lambda}$.

By using the analogy of waves on a string, if one end of the string is tied to a wall and the other extremity is free, the string can adopt a shape consistent with any wavelength. However, if both extremities of the string are tied to the walls, the waves supported by the string must have nodes at both extremities, or the waves must be featured in such way that the distance between the ends of the string must correspond to integral multiples of half wavelengths (Fig. 2). In the condition in which 
only one end of the string is tied to the wall, there no restriction to any wave vector values and, since energy $E$ is proportional to $k^{2}$, the Plot of $E$ vs. $k$ for a free electron results in a continuous parabola (Fig. 2). For the electron confined in a $1 \mathrm{~d}$ box potential, it is considered that the $L$ (extension of the confinement) is defined by equation 2 :

$$
L=\frac{n \lambda}{2}(2)
$$

Where $n$ is an integer equal $1,2,3 \ldots$ and the wave vector $k$ should be defined as equation 3 .

$$
k=\frac{2 \pi}{\lambda}=\frac{n \pi}{L}(3)
$$

Therefore, considering equation 1 , the values of $E$ allowed for the confined electron are according to equation 4 :

$$
E=\frac{\hbar^{2} \pi^{2} n^{2}}{2 m L^{2}}(4)
$$

The Plot of $E$ vs. $k$ for the confinement condition is still a parabola but with specific values that are permitted that is consistent with the quantization of the energy (Figure 2). Considering that $L$ is in the denominator, the smaller the extension of the confinement, the more widely spaced are the k values and consequently $E$ values that are permitted. The larger electron confinement, the more closely spaced are the allowed values of as well as the corresponding values of $k$ (Roduner 2006, Gleiter 2000, Wrest 2017, Rodary et al. 2007).

Figure 3 shows that the bandgap between valence and conduction band (Kubo gap) increases as the nanocluster size decreases. In a bulk material, at a given temperature, electrons are thermally populating the valence and conduction bands. However, at the same temperature, nanocrystals of the same material become an insulator. However, in a higher temperature in which the thermal energy equals the Kubo gap, the behavior of a low-

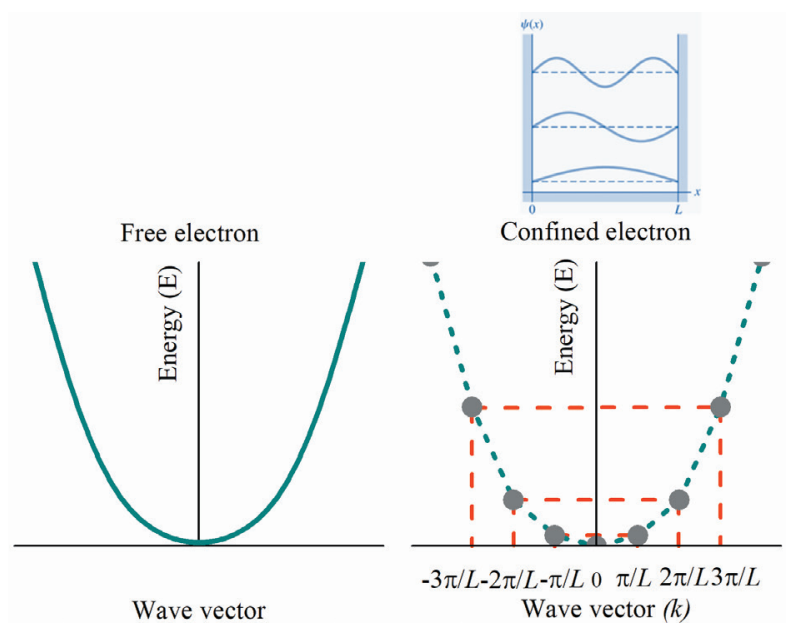

Figure 2 - The Plot of $E$ vs. $k$ for the confinement condition for free electron (left) and showing specific values that are permitted for the confined electron.

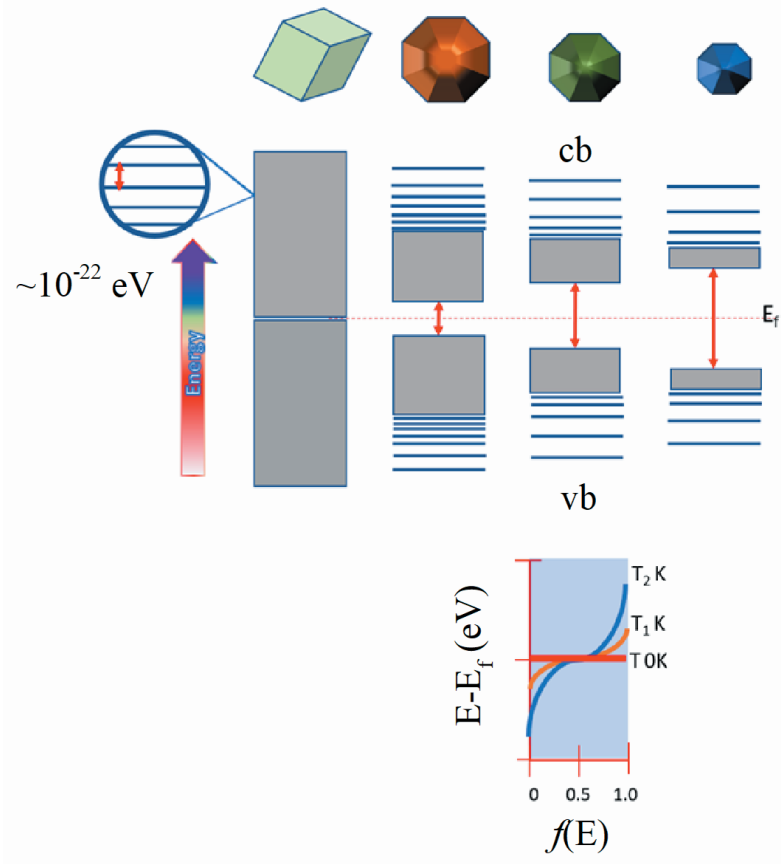

Figure 3 - The increase of the band gap energy and the density of states associated with the decrease of the number of atoms constituting a particle. From left to right, microscopic crystal (green) and out of scale, nanostructures in decreasing sizes showed above the schematic representation of valence and conduction bands $(v b$ and $c b)$. Below it is shown that at $0 \mathrm{~K}$ the Fermi level is exactly between $v b$ and $c b$. The increase of temperature leads to a finite probability that higher energy states are occupied and a finite probability low energy states are empty. 
temperature insulator changes to a semiconductor and at higher temperatures is similar to a metal (Gleiter 2000, Roduner 2006, Aneesh et al. 2014, Rao et al. 2004b).

\section{APPLICATIONS OF NANOSTRUCTURED MATERIALS}

The peculiar properties of nanostructured metals and semiconductors have been applied in a diversity of areas such as medicine, biology, energy conversion and storage, spintronics, sensing (Eustis et al. 2005, Huang et al. 2007, Majumdar et al. 2017, Zhang et al. 2018, He et al. 2010). Proteins and peptides are frequently used for the functionalization of inorganic nanoparticles to achieve specific properties such as biocompatibility, sensing, hierarchically structured materials and others (Pan et al. 2013, Ma et al. 2015, Mondal et al. 2015, Zhang et al. 2018).

\section{NANOCAGES FOR DRUG DELIVERY}

An example of nanomaterial construction for potential medical and pharmaceutical application was reported by $\mathrm{Ma}$ et al. 2015. The authors demonstrated a protocol to precisely construct an hybrid structure using the DNA binding protein from starved cells (Dps) with a single His tag (polyhistidine tag) as the building block on platforms of AuNPs functionalized $\mathrm{Ni}^{2+}$ bound nitrilotriacetic acid $\left(\mathrm{Ni}^{2+}-\mathrm{NTA}\right)$ chelates. The affinity of histidine to $\mathrm{Ni}^{2+}$ made feasible that each Dps cage was attached on the external surface. The nanocages of the Dps structure can be loaded with drugs, magnetite nanoparticulated, and enzymes (Pan et al. 2013, Ma et al. 2015, Uchida et al. 2007). Also, the physical or chemical properties of the cargos inside the Dps cages allows medical and pharmaceutical applications.

\section{MIMICKING ENZYMES}

One example of the construction of nanomaterial for application in catalysis is the association of microperoxidases, the product of the tryptic digestion of cytochrome $\mathrm{c}$, to mesoporous silica. Araujo et al. reported that the ferric microperoxidase-11 (MP-11), was entrapped in MCM-41, and resulted in a catalyst (Fe(III) MP11MCM41) with catalase and monooxygenase properties. The latter activity allowed the catalyst to oxidize phenol to 2,4-dihydroxyphenol (Araujo et al. 2007). Lykourinou et al. 2011 demonstrated that the peroxidase activity of MP-11 successfully entrapped into a mesoporous metal-organic framework (MOF) formed of nanoscopic cages was enhanced when compared with MCM-41. Another application of nanostructured materials in catalysis refers to the development of biofuel cells that will be discussed below.

\section{ENERGY CONVERSION AND STORAGE}

There is an increasing interest in the development of devices to be used in advanced energy conversion and storage such as Li-ion batteries, supercapacitors, biofuel cells, photoelectrochemical water splitting cells, solar cells, among others. The exclusive physical and chemical properties of the nanostructured materials are useful for the construction of the devices that are expected to contribute enormously for the lowcost, green, and sustainable technologies (Gärtner et al. 2012, Sivula et al. 2011, Souza and Leite 2013, Zang 2011). An important application of proteins in energy is represented by the biofuel cells. (Olyveira et al. 2013) Biofuel cells use the catalytic properties of enzymes in the purified form and in the whole microorganisms' metabolic pathways for the oxidation of biomass molecules to generate electricity (Olyveira et al. 2013). Thus, oxidereductases are key enzymes for the fabrication of biofuel cells.(de Souza et al. 2017) GOx has been largely used as a powerful enzyme-based bioanode. However, the use of GOx in biofuel cells requires a membrane due to the interference of oxygen present in the cathode compartment.(Ivnitski 
et al. 2006, Fu et al. 2009, Olyveira et al. 2013, Santos et al. 2014). Thus, glucose dehydrogenase (GDh) (de Souza et al. 2016, Luz et al. 2018), and alcohol dehydrogenase (ADH) (Pereira et al. 2017, Pereira et al. 2018) gained importance for the development of bioanodes for biofuel cells. The use of GDh and ADH is important for the development of implantable biofuel cells that are exposed to oxygen. Bioelectrochemistry also takes advantage of the nanostructured materials to improve electron transfer kinetics in bioelectrodes. The nanostructured materials allow controlling the physical and chemical properties of the associated enzymes at the molecular level. (Huczko 2000) A diversity of nanomaterials have been used to modified electrodes such as carbon nanotubes, metallic nanoparticles, and others. Another application of proteins associated with nanostructured materials in energy conversion, harvesting, and storage is represented by biosolar cells based on light-harvesting proteins (Somasundaran et al. 2011, Ihssen et al. 2014, Purchase and de Groot 2015). The protein-based bio-solar cells are promising to face the demand for green and sustainable energy. The desirable characteristics of light-harvesting proteins to be applied in energy conversion and storage are thermal stability and broadband absorption. Light harvesting proteins alone or whole photosynthetic reaction centers have been used for the fabrication of hybrid bio-inorganic PV and PEC devices. These proteins and protein/dye complexes can sensitize nanostructured metal and semiconductor surfaces. Ihssen et al. present a review of a diversity bio-inorganic electrodes such as $\mathrm{TiO}_{2} /$ bacteriorhodopsin, $\mathrm{TiO}_{2} / \mathrm{WO}_{3} /$ photosynthetic reaction center, $\mathrm{TiO}_{2} / \mathrm{ZnO} / \mathrm{PSI}, \alpha-\mathrm{Fe}_{2} \mathrm{O}_{3} / \mathrm{C}$ phycocyanin, gold/PSI and others.(Ihssen et al. 2014) An extra advantage of the use of proteins for light harvesting and energy conversion is the possibility to tune their properties using mutation. As an example, mutants of bacteriorhodopsin can be produced with low cost and exhibits high quantum efficiency and thermal robustness. Photosynthesis converts solar energy to chemical energy that is abundantly stored as organic matter (Somasundaran et al. 2011, Purchase and de Groot 2015). Cytochrome c can also be used in systems that mimic photosynthesis with applications extensive to spintronic as discussed below.

\section{SPINTRONICS AND NANOROBOTS}

Spintronics is emergent technology in which both electronic charge and electron spin carry information.(Abbott et al. 2018, Dong et al. 2018, Lou et al. 2018, Mai et al. 2018, Parameswaran and Tian 2018) The spintronic is expected to be applied in electronics that will combine standard microelectronics with spin-dependent effects resulting from the interaction between the spin of the carriers and external magnetic fields. Spintronic is an advance in the field of information which, usually, has the storage based on magnetism and the processing based on charge. The field of spintronic emerged fast since the discovery of giant magnetoresistance (GMR) effect in 1988, awarded A. Fert and P. Grunberg with the Nobel Prize in Physics in 2007. More recently it was discovered the chiral induced spin selectivity (CISS) effect, that allows the injection of spin-polarized current without the use of a permanent magnetic layer. The CISS effect results that electron transport is spinselective through chiral molecules.(Zhang et al. 2018) In this regard, proteins and peptides are chiral molecules with a helical structure that are highly efficient spin filters. Cytochrome $\mathrm{c}$ is an interesting molecule for application in energy conversion and spintronics (Dias et al. 2012, Araújo-chaves et al. 2014, Mondal et al. 2015). Dias et al. reported the molecular interaction of cytochrome $\mathrm{c}$ with two $\mathrm{TiO}_{2}$ structures: $\mathrm{P} 25 \mathrm{TiO}_{2} \mathrm{NPs}$ and titanate nanotubes.(Dias et al. 2012) Both the $\mathrm{TiO}_{2}$ structures were able to promote photoreduction of 
the cytochrome $\mathrm{c}$ heme iron. Titanate nanotubes were able of adsorbing 2.3-fold more cytochrome c $\left(1.75 \mu \mathrm{g} \mathrm{m}^{-2}\right)$ than $25 \mathrm{TiO}_{2}$ NPs $\left(0.75 \mu \mathrm{g} \mathrm{m}^{-2}\right)$. $\mathrm{P} 25 \mathrm{TiO}_{2}$ NPs reduced cytochrome $\mathrm{c}$ that remained in solution while titanate nanotubes were able to reduce adsorbed protein. The adsorption on the titania surfaces did not change the redox properties of cytochrome $c$. Cytochrome reduced by the titania materials was re-oxidized by peroxides and could be reversibly reduced. In these systems, the UV-illumination of the semiconductor materials promotes the formation of the electron $\left(\mathrm{e}^{-}\right)$hole $\left(\mathrm{h}^{+}\right)$pair. A similar process was observed using nanoparticulated hematite (Araújo-chaves et al. 2014). The electron is transferred from the conduction band to cytochrome c, and water splitting supplies the electron for the valence band vacancy with the formation of hydroxyl radical that for this system, was trapped by DMPO spin trapping and detected by EPR. The redox photoreaction occurring in the system cytochrome/ semiconductor is a mimetic of the photosynthesis (Figure 4) according to Dias et al. 2012. However, in the mechanism of water splitting promoted by semiconductors, water splitting has hydroxyl radicals as intermediates of molecular oxygen evolution. The hydroxyl free radical can combine to form hydrogen peroxide or molecular oxygen and two protons that could be reduced to hydrogen gas. However, in the latter process, molecular oxygen is produced in the singlet excited state, and an energy barrier of $1 \mathrm{eV}$ is added to the process of hydrogen production. The presence of a chiral molecule such as cytochrome c can act as a spin filter in the electron transfer favoring the production of the ground state triplet molecular oxygen rather than hydrogen peroxide. It was surprising that cytochrome $\mathrm{c}$ remained reduced in a medium with high production of hydrogen peroxide. Future studies are necessary to investigate if a selective spin reduction of cytochrome c occurs favoring molecular oxygen evolution. In this condition, the system cytochrome c/semiconductors mimics photosynthesis. Another important and amazing advance involving the interaction of proteins and whole cells with metallic nanostructures is the development of nano/micromotors and robots (Sitti 2018). The functional part of micro/ nanorobots is fabricated with synthetic materials that are frequently toxic. A strategy for getting biocompatibility is the use of cells and biomaterials such as proteins.

\section{CHARACTERISTIC OF PROTEIN AND PEPTIDE STRUCTURES USEFUL FOR THE SYNTHESIS AND STABILIZATION OF NANOSTRUCTURES}

Proteins and peptides have chemical and structural characteristics that contribute both their use to the in-situ synthesis, stabilization, and functionalization of metallic nanoparticles. Proteins and peptides have functional groups that act as chelating and reducing agents of the metal ions. The bottomup synthesis of metallic nanoparticles from the corresponding metallic salts requires a reducing agent to convert the salt ion $\left(\mathrm{M}^{\mathrm{n}+}\right)$ to the atomic form $\left(\mathrm{M}^{\circ}\right)$ (Miranda et al. 2016). The reducing role played by cysteine and lysine residues for reducing the metal ions to the atomic form to produce the nanoclusters is well known (Xia et al. 2009, Chen 2014, Spicer and Davis 2014, Siriwardana et al. 2015). Proteins and peptides have threedimensional structures that create specific microenvironments for the nucleation process and nanoparticle growth. In the crystalline growth process of metallic nanoparticles, functional groups of proteins and peptides have specific affinity for certain metallic facets. Thus, proteins and peptides direct the crystalline growth of the nanostructures to a diversity of size and shape (Tofanello et al. 2016). Proteins, and peptides are also largely used for the stabilization and functionalization of a diversity of nanostructured materials providing properties such as biocompatibility, plasmonenhanced catalysis, sensing, fabrication of micro/ 


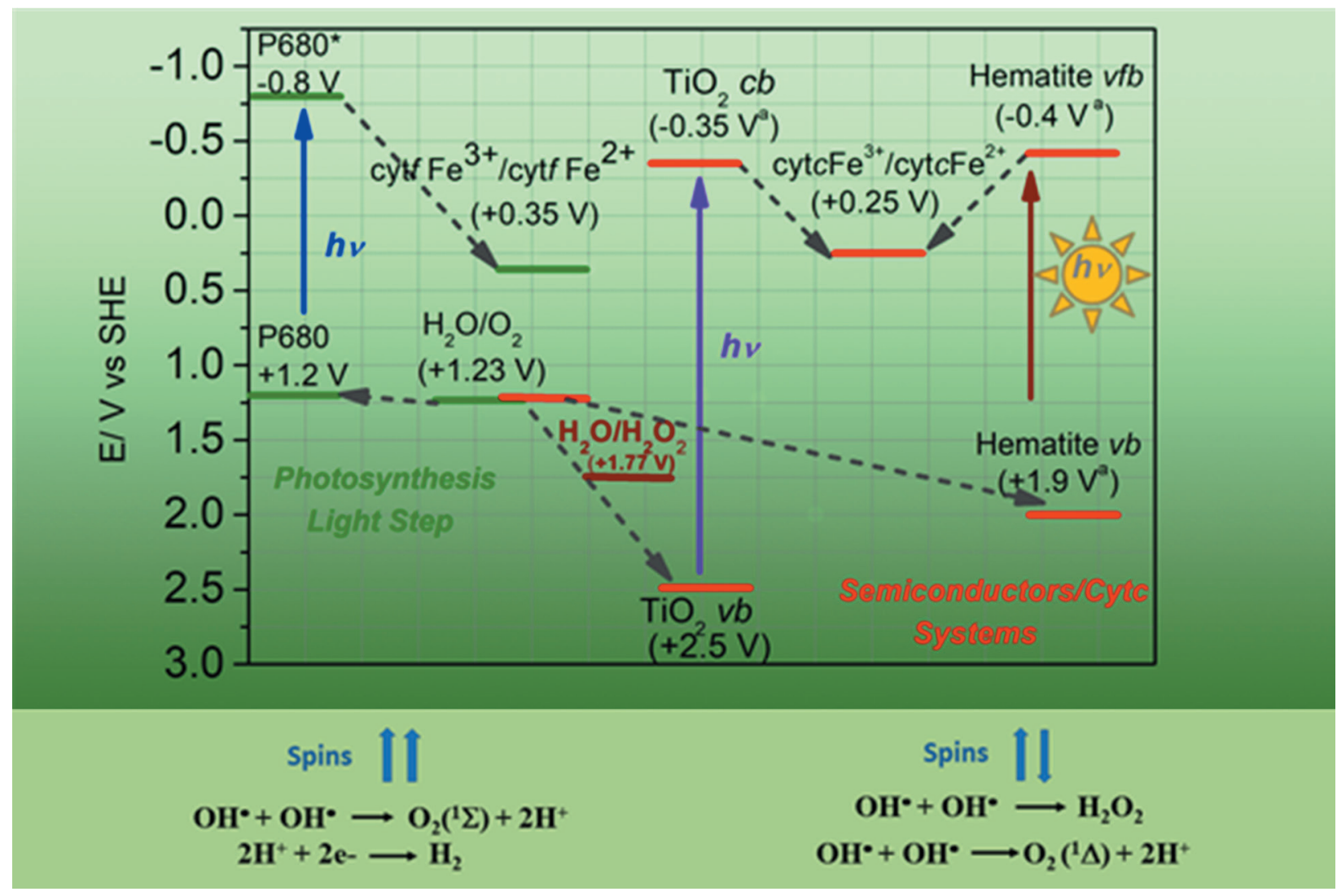

Figure 4 - A comparative view of the redox potentials of the semi-reactions involving cytochrome $f$ in the photo-phosphorylation process and cytochrome c reduction in the biohybrid systems of semiconductors and cytochrome c. Redox potentials at $\mathrm{pH} 7.0$ (vs. SHE) according to ref. Dias et al. 2012. For the photo-reduction of cytochrome $f$, the intermediate steps of the have been omitted for improving clarity. Bellow, it is depicted the spin-directed competitive formation of hydrogen gas and hydrogen peroxide.

nanomotors and others. The mechanisms involved in the reducing step of metallic nanoparticle synthesis promoted by proteins and peptides are complexes and present specific peculiarities. Pereira et al. studied the molecular interactions and redox processes occurring during the synthesis of palladium nanoparticles associated to glucose oxidase (GOx-PdNPs) in a supramolecular arrangement (Pereira et al. 2011). GOx is associated to the cofactor FAD that constitute the redox center of the enzyme. During the synthesis of PdNPs, unexpectedly Pd ions and FAD were reduced. The synthesis occurs in two steps, the conversion of $\mathrm{Pd}$ ions to Pd0 reduction and the formation of a supramolecular aggregate of $80 \mathrm{~nm}$ containing 3.5 nm sized PdNPs associated with multiples units of GOx. Therefore, it was proposed that the thiol group of the cysteine 521 residue of GOx interacts with Pd ions leading to Pd reduction. Probably due to the drastic structural changes exhibited by the enzyme, reducing amino acid side chains are positioned close to FAD leading to its concomitant reduction. The mechanism characterizes the existence of competition among Pd ions and FAD for the reduction in such a way that formic acid was necessary as a co-adjuvant reducing agent for the PdNP growing. In another study, Tofanello et al. demonstrated that not only the presence of cysteine residues in a peptide structure is the warranty of an adequate reducing capacity for the synthesis of gold nanoparticles (GNPs) (Tofanello et al. 2016). For that study, alkaline peptides AAAXCX (X = lysine or arginine residues) were designed having as inspiration the conserved motif of the enzyme 
thioredoxin (Tofanello et al. 2016). The alkaline peptides were compared with free cysteine, the counterpart acidic peptides $\gamma$-ECG (glutathione) and AAAECE, as well as the neutral peptide AAAACA. The results demonstrated that the amino acids neighboring a cysteine residue modulates the synthesis of GNPs in a $\mathrm{pH}$-dependent manner. Like it was observed for bovine and human albumin used for the synthesis of GNPs, for the designed peptides it was corroborated that gold speciation and the peptide structure also influenced the synthesis and stabilization of GNPs (Miranda et al. 2016). Most often, the proteins direct the anisotropic growth of $\mathrm{Au}^{0}$ into plate-like structures using mechanisms in which environmental variables such as temperature and $\mathrm{pH}$ play key roles in the anisotropic growth of gold nanoparticles (Xia et al. 2009, Barnard 2012). Figure 5 shows the field emission scanning electron microscopy (FESEM) images of gold nanostructures produced by using bovine serum albumin as reducing and stabilizing agents. The nanoplates were produced either truncated triangular or hexagonal in geometry with very smooth edges with thickness at the nanoscale (Figure 5). Like to the results previously obtained with the peptide AAAKCK, the use of albumin at $\mathrm{pH} 11$ for the synthesis of gold nanostructures also results in polydispersity in shapes and sizes that was probably promoted by twinning that is a common process for face-centered cubic (fcc) metals (Barnard 2012, Niu et al. 2013, Polte 2015). The random twinning could result from a fast and non-uniform reduction of gold ions. In a review, Carmona-Ribeiro et al. describe that the association of peroxidases or systems with peroxidase-like activity with different types of nanostructures including nanoparticles, nanotubes, thin films, liposomes, micelles, nanoflowers, and nanorods have been used to improve catalytic activity, reusability, and targeting. These strategies are particularly important as peroxidases are enzymes largely used for several technological and biomedical applications (Carmona-Ribeiro et al. 2015). Some examples of effects of nanostructures on the catalytic activity of enzymes are described herein.

\section{ENZYME-FUNCTIONALIZED NANOSTRUCTURES OF NOBLE METALS}

The association of proteins with catalytic activity, i.e., the enzymes, with the metallic nanoparticles has attracted researchers because these associations can improve specific desirable characteristics of the enzymes. Enzymes can be associated with metallic nanoparticles that were previously synthesized with the use of conventional reducing agents such as sodium borohydride or sodium citrate. Another alternative is the synthesis of metallic nanoparticles in-situ by using the proteins as reducing and stabilizing agents (Miranda et al. 2016, Tofanello et al. 2016). In the present review, metallic nanoparticles functionalized with three different enzymes will be presented: bromelain, luciferase, and $\beta$-glycosidase.

Bromelain (Bro) is a mixture of proteases extracted from a pineapple plant (Ananas comosus). Bromelain has biotechnological (food, cosmetic, textile) and therapeutic applications as anti-inflammatory, antiedematous, fibrinolytic and antithrombotic (Dutta and Bhattacharyya 2013). The biological application requires cell uptake, low toxicity, and specificity to a target (Salata 2004, Britto and Nantes-Cardoso 2017). These characteristics can be attained by the association to nanoparticles, particularly, gold nanoparticles (GNPs). Our team have been studying one pot and green methods for the synthesis of biologically compatible GNPs using the purified extract from different parts of the pineapple and a commercial stem bromelain added to a tandem combination of three HEPES buffer and $\mathrm{HAuCl}_{4}$ concentrations that were characterized by color change of the solutions, UV-visible and Raman spectroscopies 


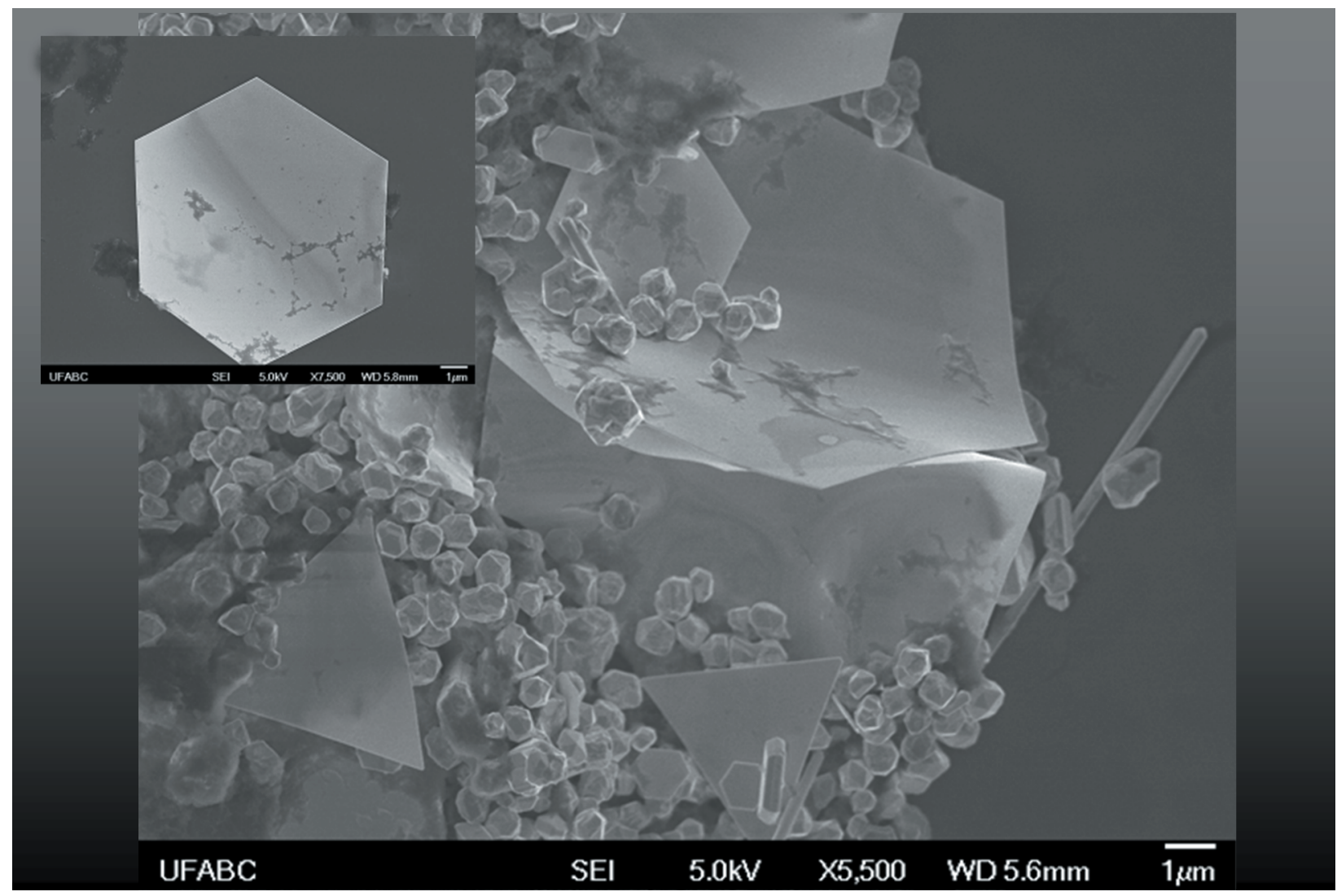

Figure 5 - FESEM images of gold nanoplates produced either truncated triangular or hexagonal in geometry with very smooth edges with thickness at the nanoscale.

(Figures 6, 7 and 8, respectively). The Raman spectra that are shown in Figure 8 compares the pineapple extracts obtained from fruit (red dashdot line), crown (green dash-dot line) and peel (dark cyan dash-dot line) with the corresponding gold nanoparticles obtained by in-situ synthesis using the respective extracts (red, green and dark cyan solid lines). The identification of proteins in the extracts is evidenced by the presence of bands amide I, II and III that involves the vibrations of $\mathrm{C}=\mathrm{O}, \mathrm{C}-\mathrm{N}$ and $\mathrm{N}-\mathrm{H}$ groups of a peptide bond (amide bond), respectively (Tofanello et al. 2016). The characteristic spectral features of proteins were also identified in the samples of GNPs synthesized with the respective extracts, and absent in GNPs synthesized using citrate. The BroGNPs were also characterized by zeta potential that ranged from
-15 to $-20 \mathrm{mV}$ and was consistent with the colloidal stability exhibited by the suspension.

GNPs produced with $2.5 \mathrm{mM}$ buffer, and the three $\mathrm{HAuCl}_{4}$ concentrations remained stable after 10 days. GNPs produced with $0.2 \mathrm{mM}$ buffer remained stable only using $0.4 \mathrm{mM}$ of $\mathrm{HAuCl}_{4}$.

The catalytic activity BroGNPs on hydrolyzed gelatin was studied in a comparatively with soluble free Bro and collagenase (Figure 9). Figure 9 shows the melting of gelatin gels resulting from proteolytic digestion by free Bro, collagenase, and BroGNPs. Collagenase from Clostridium histolyticum was used as the positive control. Collagenase promoted extensive digestion of gelatin leading to the melting of gelatin gel. In comparison with collagenase free, Bro was less efficient in promoting gelatin digestion, and its proteolytic activity was partially inhibited by E-64. Bro associated with GNPs was less 


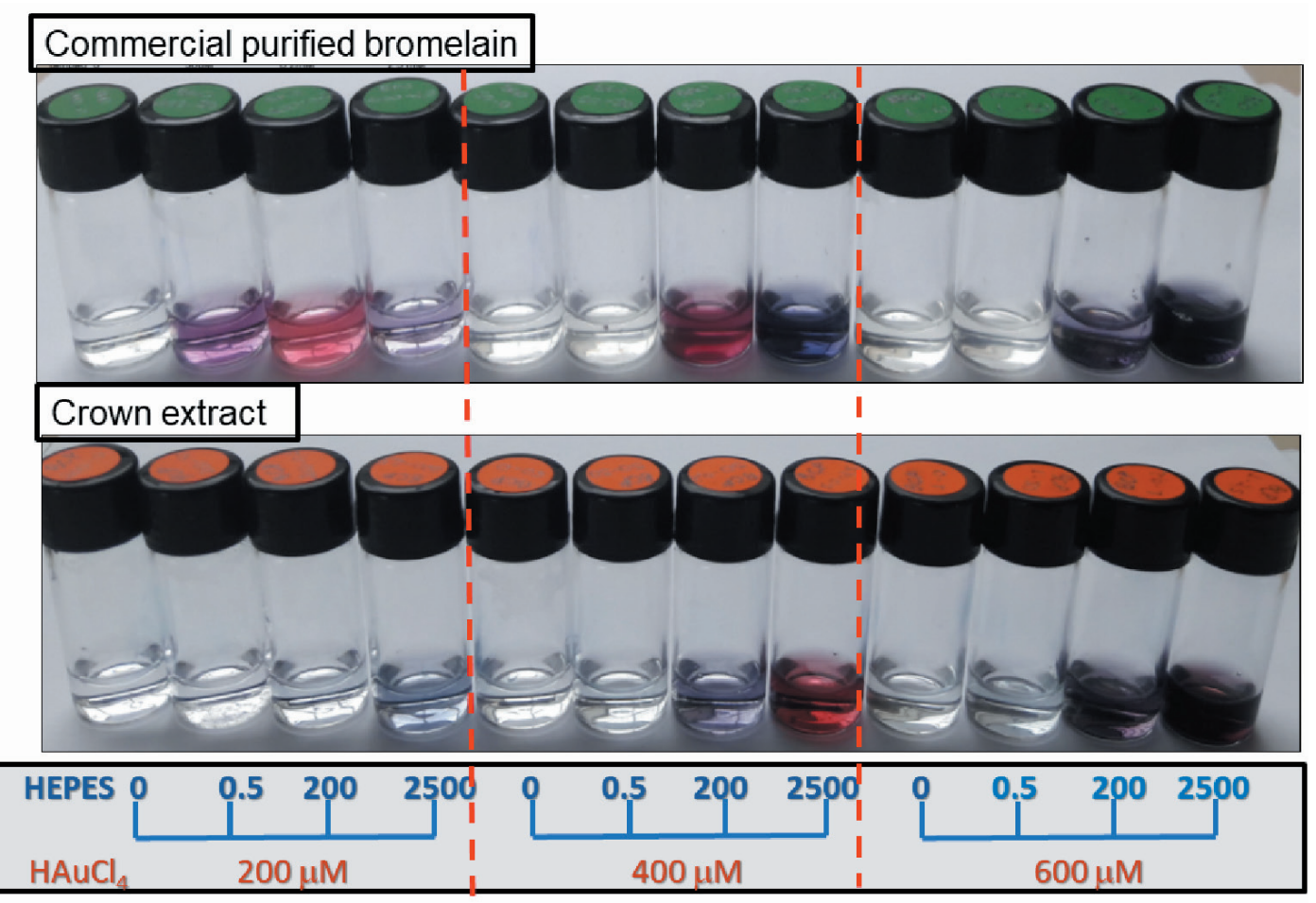

Figure 6 - Snapshots of the solution colors obtained after the synthesis of GNPs using bromelain at the different conditions indicated in the figure.

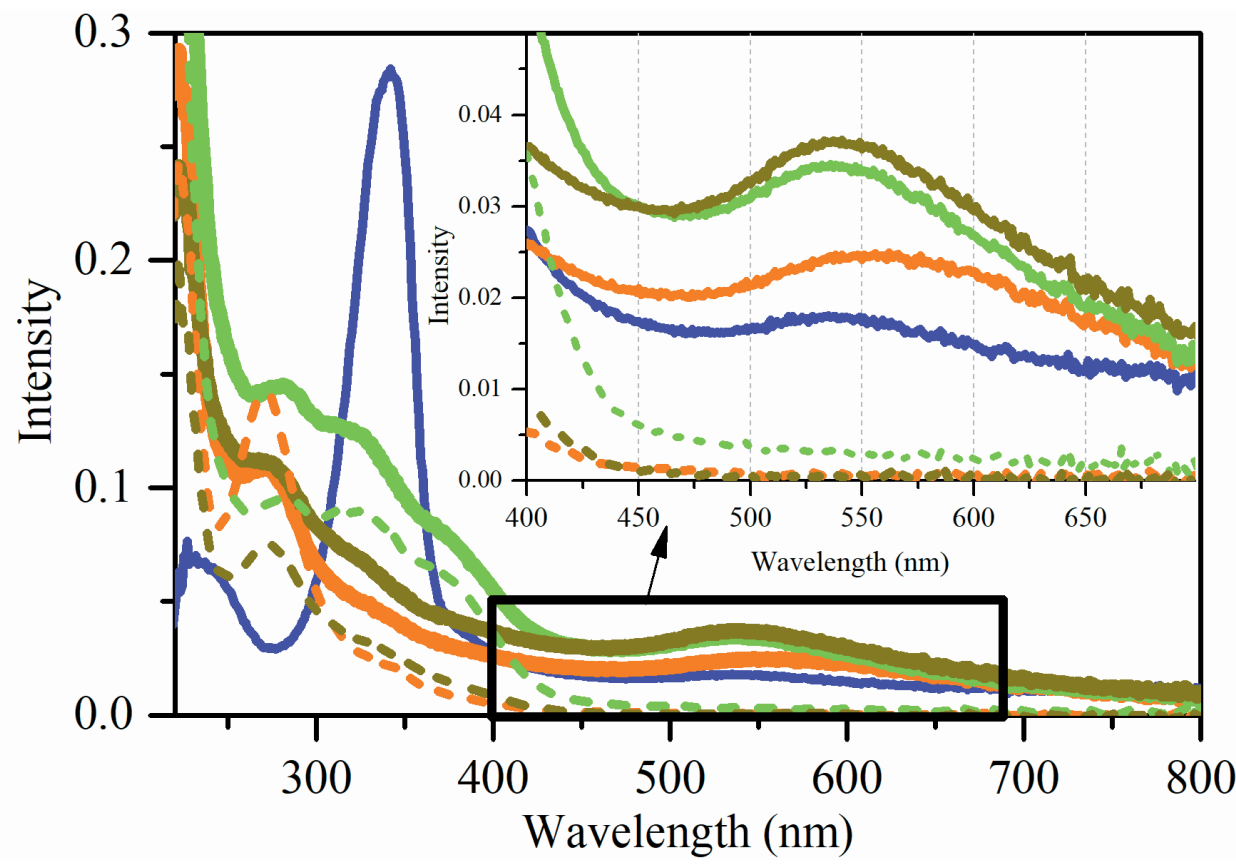

Figure 7 - UV-Vis spectral changes during the synthesis of gold nanoparticles using bromelain purify extract from the following parts of the pineapple: orange line - fruit, light green line - crown, dark green line - peel. Purple line - control (2.5 mM HEPES). Spectra obtained before the detection of plasmonic bands are represented as dashed lines. The inset shows a zoom of the plasmonic bands. 


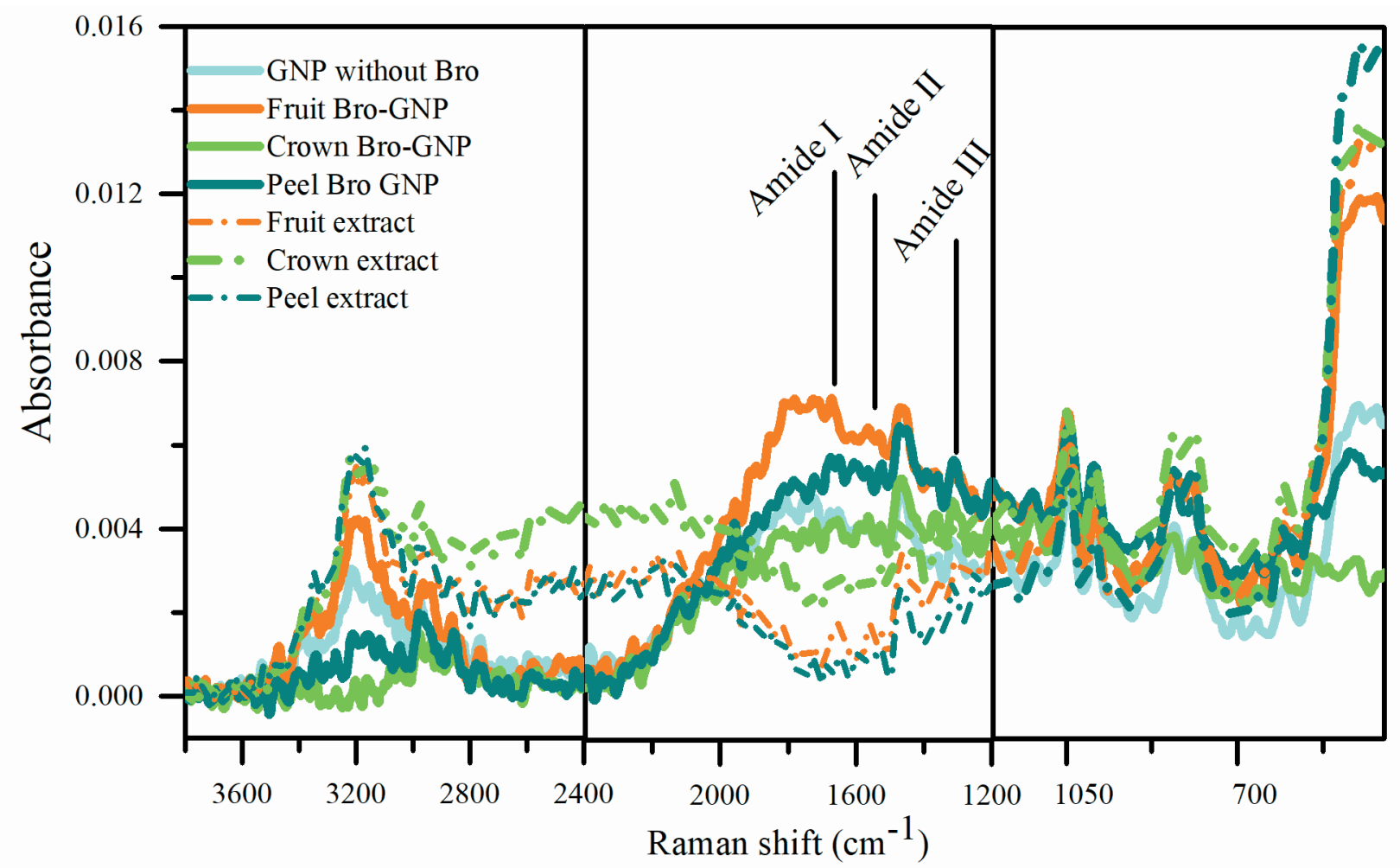

Figure 8 - Raman spectroscopy consistent with the particles covered by peptides due to the presence of Amide I, II and III bands.

efficient to promote gelatin than free Bro. However, its activity was inhibited by E-64. Therefore, the process of synthesis and functionalization of GNPs using Bro resulting in a type of enzyme purification by selecting the E-64 sensitive fraction. Another interesting use of enzymes for the synthesis and functionalization of metallic nanoparticles is obtained with luciferases. Luciferases are enzymes that catalyze bioluminescent reactions used for high-throughput screening, particularly the bioluminescence-based assays. Bioluminescence is generated by highly exothermic, enzymatically catalyzed chemical reactions in which the energy of chemical bonds of organic compounds is converted preferably into visible light. In these reactions, molecules of luciferins are oxidized by oxygen, producing electronically excited molecules that decay by emitting light. These reactions are catalyzed by the enzymes called luciferases. In click beetle luciferases, catalyzes the oxygenation of luciferin using $\mathrm{Mg}^{2+} \mathrm{ATP}$ to yield excited state of oxyluciferin that emits light. These luciferases have served as study models of structure and function, especially between structure and bioluminescence spectra, resulting in important scientific discoveries about how the structure of these enzymes determines bioluminescence colors. New luciferases with modified properties for bioanalytical purposes have been developed. Currently, luciferases are applied as bioluminescent markers of gene expression in mammalian cells, in circadian rhythm studies in a neuronal cell, and in bacterial biosensors for bioprospecting of microbicidal agents and toxicity. Considering the several technological applications of the luminescent luciferin-luciferase system, the modulation of luciferase activity by the association with nanostructures is yet not well exploited. Some accounts about the effect of nanoparticles on luciferase activity have been restricted to the changes of the enzyme structure modulated by association with nanostructures. The association of enzymes to nanoparticles can provide several 


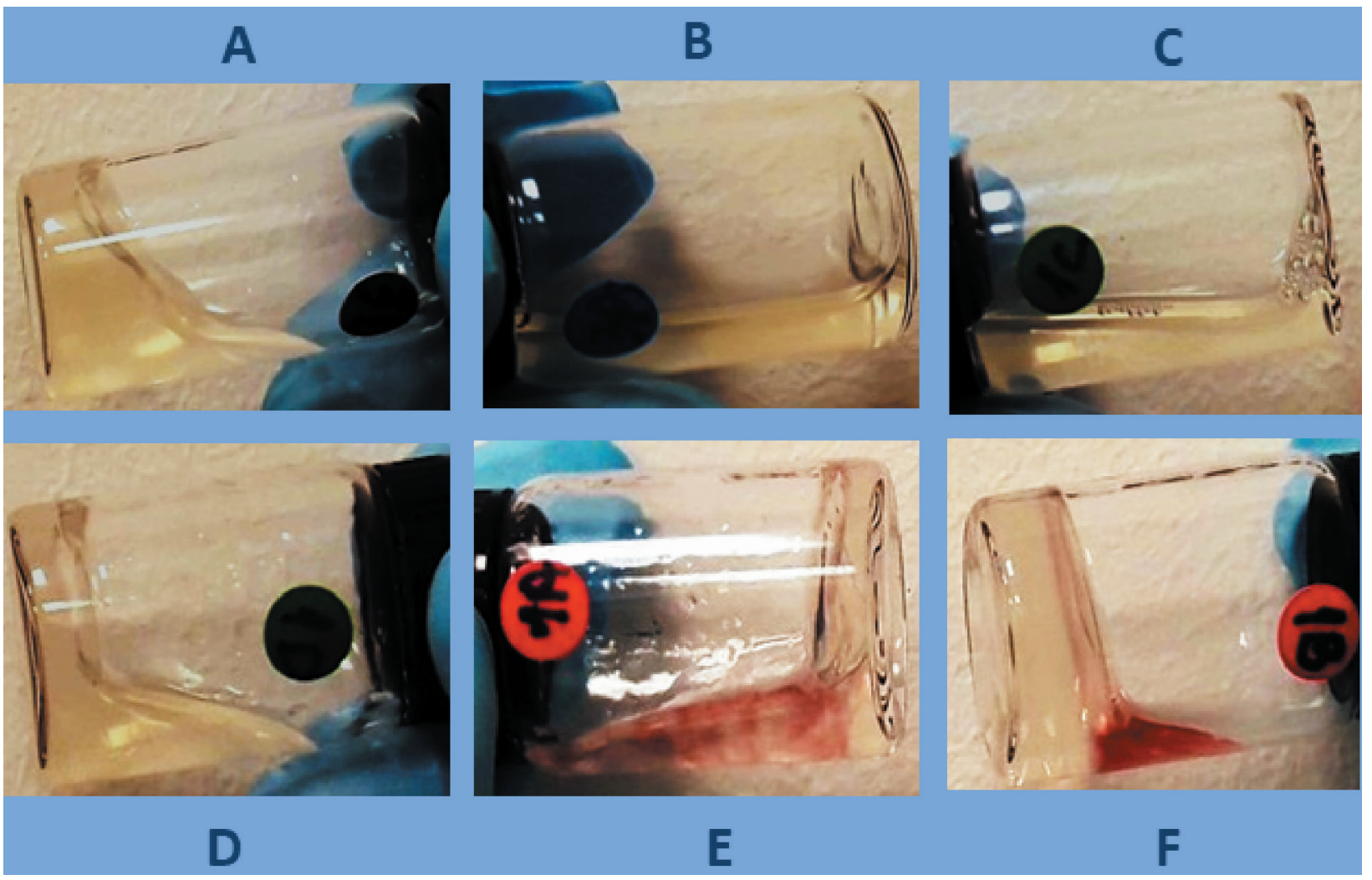

Figure 9 - Snapshots of gelatin before (a) and after the proteolytic activity of collagenase (b), free Bro (c), free Bro plus E-64 (d), BroGNPs (e) BroGNPs plus E-64 (f).

advantages such as enzyme stability, efficiency, and recycling. Considering that, the study of the structure and activity of firefly luciferases associated with metallic nanoparticles shows promising. In a first exploration, our group in collaboration with the group of professor Vadim Viviani initiated studies concerning the production of metallic nanoparticles functionalized with luciferases and a first account was presented in 20th International Symposium on Bioluminescence and Chemiluminescence by the study intitled Click Beetle Luciferase for Synthesis and Stabilization of Metallic Nanoparticles: Potential Nanotechnological Applications and is now composing a manuscript for publication.

Regarding the enzyme $\beta$-glucosidase, Araujo et al. has published its use in the successful insitu synthesis of silver nanoparticles (Araújo et al. 2017, 2018, Cruz et al. 2018). The enzymes $\beta$-glucosidases have many processes and industrial applications. One important application of $\beta$-glucosidases is the production of biofuel from biomass. In the article published by Araujo et al. it was described the photobiosynthesis of stable and functional silver/silver chloride nanoparticles (Ag/AgCl-NPs) with the use of hyperthermostable bacterial $\beta$-glucosidases. The synthesis resulted in $\mathrm{Ag} / \mathrm{AgCl}-\mathrm{NPs}$ coated and stabilized by $\beta$-glucosidases with a preserved enzymatic activity that is important for biotechnological applications (Araújo et al. 2017). In a subsequent study, it was demonstrated that the contents of $\mathrm{Ag}^{0}$ could be easily controlled by using different $\mathrm{Ag}^{+} / \mathrm{Cl}^{-}$ ratios (Araújo et al. 2018). The plasmonic Ag/ $\mathrm{AgCl} \mathrm{NPs}$ that was coated by the protein have photocatalytic activity and promoted methylene blue photodegradation. The dye degradation by $\mathrm{Ag} / \mathrm{AgCl} \mathrm{NPs}$ was facilitated by the protein layer capping the nanoparticles surface that adsorbed the 
dye close to the catalytic surface. Furthermore, the protein could avoid the recombination rate of the electron-hole pairs, similarly to others previously described organic-molecules-coated nanoparticles (Kumar et al. 2017). In a similar protocol described for the synthesis of $\mathrm{Ag} / \mathrm{AgCl} \mathrm{NPs}$, the replacement of chloride by bromide resulted in $\mathrm{Ag} / \mathrm{AgBr}-\mathrm{NPs}$ under blue light illumination. The content of $\mathrm{Ag} 0$ in the $\mathrm{Ag} / \mathrm{AgBr}-\mathrm{NPs}$ could also be controlled with different $\mathrm{Ag}+/ \mathrm{Br}-$ ratios in the synthesis process. The photocatalytic activity on the degradation of methylene blue was also observed by the plasmonic protein-coated $\mathrm{Ag} / \mathrm{AgBr}-\mathrm{NPs}$.

\section{CHALLENGES AND PERSPECTIVES}

The fabrication of nanostructured materials associated with proteins and peptides has experienced tremendous expansions and advances that in turn poses new challenges. Proteins and peptides associated with nanostructure surfaces create a bio-nano interface that present properties distinct of the separated materials. For biological and technological applications, it is important a profound understanding of both the thermodynamics and kinetics of the protein corona formation considering the synthesis in situ using the biological molecules or the capping of prefabricated nanostructures. New tools have emerged as contributors for better comprehension and characterization of proteincapped nanostructures, and mainly, computational simulations have provided crescent contributions. Considering the theranostic application of proteincapped nanostructures, it is essential to conceive that the original protein corona can be exchanged the proteins present in the biological fluids (Heath 2003, LaVan et al. 2003, Sanhai et al. 2008, Mahmoudi et al. 2011, Monnier et al. 2014). The evolution of protein corona of NPs introduced in a biological fluid has impacts and challenge for the advances in new tools to investigate the bio-nano interface. Another question is that proteins can suffer unfolding upon adsorption on nanostructures and become potentially harmful leading to diseases such as amyloidoses. In this regard, the current studies of our research groups, there are cases of both unfolding and stabilization of protein native structures. The synthesis in situ of PdNPs using GOx (Pereira et al. 2011) and GNPs using luciferase (unpublished results) led to significant changes in the respective native structure of the respective proteins whereas bromelain and albumin (Miranda et al. 2016) retain and further stabilized native structures. For technological applications such as spintronic in which the helical structure of proteins and peptides are responsible for the capacity to act as a spin filter, the structural stability is critical. Therefore, the use the highly stable hemeproteins such as cytochrome $\mathrm{c}$ is promising for these applications. The development of spintronics-based devices is a challenging task that requires innovative and precise fabrication techniques. The spintronics area requires extensive investigation, knowledge of materials science, physics, computational simulations and consequently the work in an interdisciplinary team (Joshi 2016). Disregard the applications, the synthesis reproducibility and colloidal stability of nanoparticles are others essential questions to consider. The application of the bio-nano interfaces in electronic is an emerging area. For biological and technological applications, the perspective is no more the development of a multiplicity of nanoparticles and their static assembly, but on the fabrication of communicating systems working by interacting with different nanostructures (Grzybowski and Huck 2016, Zhang and Lieber 2016). The applications of the communicating systems based on the dynamic interactions of nanostructures are sensing, drug delivery, Boolean logical operations, among others (Bain and Staniland 2015, Grzybowski and Huck 2016, Zhang and Lieber 2016). 


\section{CONCLUSIONS}

Proteins and peptides have many desirable characteristics for the synthesis, functionalization, and applications of metallic nanostructures. Proteins and peptides have several functional groups, with reducing capacity, among which the thiol group present in the cysteine residues. The cysteine thiol group besides the reducing capacity coordinates strongly with the metallic surface of the nanoparticles and stabilizes the functionalization of these structures. Proteins and peptides form threedimensional structures that act as templates and direct the crystalline growing of nanostructures. Functionalization of metallic nanoparticles with proteins and peptides confers biocompatibility, catalytic properties, stability and even facilitates the development of advanced materials such as those applied in spintronics. Moreover, proteins and peptides can be obtained from natural extracts and allow the synthesis of metallic nanostructures by facile, green, and one pot methods. The general challenges are secure, fast, green and reproducible fabrication of nanomaterials. For biological applications the characteristics of biocompatibility and degradability are important. For technological applications, the principal challenge is the large gap between the theoretical models that are predicted in the academy and the devices that are used by the industry. Strategic partnerships industry/academy are necessary to the practical applications.

\section{ACKNOWLEDGMENTS}

Authors thank to Aryane Tofanello for the contribution with gold nanoplate synthesis, David da Mata Lopes for the technical assistance, FAPESP 2015/17688-0, 2017/02317-2, CAPES, finance code-001 and $\mathrm{CNPq}(\mathrm{SisNano})$, Multiuser Central Facilities (CEM-UFABC) and NBB/UFABC for the experimental and financial support. E.B. is a fellow of CAPES ILN-C is fellow of CNPq (309247/2017-9).

\section{AUTHOR CONTRIBUTIONS}

A.M.M.B., E.B., and L., R. M. contributed with results and corresponding text about of bromelain, luciferase, and semiconductors, respectively, A.J.C.L. contributed with SEM images and revised the text about nanostructured materials and I. L. $\mathrm{N}-\mathrm{C}$ coordinate, wrote and made the artwork of the final version of the manuscript.

\section{REFERENCES}

ABBOTT J, YE T, HAM D AND PARK H. 2018. Optimizing Nanoelectrode Arrays for Scalable Intracellular Electrophysiology. Acc Chem Res 51: 600-608.

ANEESH PK, NAMBIAR SR, RAO TP AND AJAYAGHOSH

A. 2014. Electrochemical synthesis of a gold atomic cluster-chitosan nanocomposite film modified gold electrode for ultra-trace determination of mercury. Phys Chem Chem Phys 16: 8529-8535.

ARAÚJO-CHAVES JC, TOFANELLO A, YOKOMIZO CH, WALDEMIR M, SOUZA FL AND NANTES IL. 2014 Cytochrome $\mathrm{c}$ as an electron acceptor of nanostructured titania and hematite semiconductors C. J Energy Chall Mech 1: 1-9.

ARAUJO JC ET AL. 2007. Peroxidase catalytic cycle of MCM-41-entrapped microperoxidase-11 as a mechanism for phenol oxidation. J Nanosci Nanotechnol 7(10): 36433652.

ARAÚJO JN, TOFANELLO A, DA SILVA VM, SATO JAP, SQUINA FM, NANTES IL AND GARCIA W. 2017. Photobiosynthesis of stable and functional silver/silver chloride nanoparticles with hydrolytic activity using hyperthermophilic $\beta$-glucosidases with industrial potential. Int J Biol Macromol 102: 84-91.

ARAÚJO JN, TOFANELLO A, SATO JAP, CRUZ LS, NANTES-CARDOSO IL, FERREIRA FF, BATISTA BL AND GARCIA W. 2018. Rapid Synthesis via Green Route of Plasmonic Protein-Coated Silver/Silver Chloride Nanoparticles with Controlled Contents of Metallic Silver and Application for Dye Remediation. J Inorg Organomet Polym Mater. 28: 2812-2818.

BAIN J AND STANILAND SS. 2015. Bioinspired nanoreactors for the biomineralisation of metallic-based nanoparticles for nanomedicine. Phys Chem Chem Phys 17: 15508-15521.

BARNARD AS. 2012. Direct Comparison of Kinetic and Thermodynamic Influences on Gold Nanomorphology. Acc Chem Res 45: 1688-1697.

BRITTO AM AND NANTES-CARDOSO IL. 2017. Pay Attention to the Therapeutic Applications of Plant 
Peptidases: New Perspectives with Nanotechnology. Org Med Chem Int J 2: 5-7.

CARMONA-RIBEIRO AM, PRIETO T AND NANTES IL. 2015. Nanostructures for peroxidases. Front Mol Biosci 2: 50 .

CHEN J. 2014. Noble Metal Nanoparticle Platform, Cancer Theranostics.

CRUZ GF, TOFANELLO A, ARAÚJO JN, NANTESCARDOSO IL, FERREIRA FF AND GARCIA W. 2018. Fast One-Pot Photosynthesis of Plasmonic Protein-Coated Silver/Silver Bromide Nanoparticles with Efficient Photocatalytic Performance. J Inorg Organomet Polym Mater 28: 2056-2062.

DE SOUZA FL AND LEITE ER. 2013. Nanoenergy. Berlin, Heidelberg: Springer Berlin Heidelberg.

DE SOUZA JCP, IOST RM AND CRESPILHO FN. 2016. Nitrated carbon nanoblisters for high-performance glucose dehydrogenase bioanodes. Biosens Bioelectron 77: 860865.

DE SOUZA JCP, SILVA WO, LIMA FHB AND CRESPILHO FN. 2017. Enzyme activity evaluation by differential electrochemical mass spectrometry. Chem Commun 53: 8400-8402.

DIAS CFB ET AL. 2012. Photo-induced electron transfer in supramolecular materials of titania nanostructures and cytochrome c. RSC Adv 2: 7417.

DONG R, CAI Y, YANG Y, GAO W AND REN B. 2018. Photocatalytic Micro/Nanomotors: From Construction to Applications. Acc Chem Res 51: 1940-1947.

DUTTA S AND BHATTACHARYYA D. 2013. Enzymatic, antimicrobial and toxicity studies of the aqueous extract of Ananas comosus (pineapple) crown leaf. J Ethnopharmacol 150: 451-457.

EUSTIS S, HSU HY AND EL-SAYED MA. 2005. Gold nanoparticle formation from photochemical reduction of $\mathrm{Au}^{3+}$ by continuous excitation in colloidal solutions. A proposed molecular mechanism. J Phys Chem B 109: 4811-4815.

FU C, YANG W, CHEN X AND EVANS DG. 2009. Direct electrochemistry of glucose oxidase on a graphite nanosheet-Nafion composite film modified electrode. Electrochem Commun 11: 997-1000.

GÄRTNER F, LOSSE S, BODDIEN A, POHL MM, DENURRA S, JUNGE H AND BELLER M. 2012. Hydrogen evolution from water/alcohol mixtures: Effective in situ generation of an active $\mathrm{Au} / \mathrm{TiO} 2$ catalyst. ChemSusChem 5: 530-533.

GEONMONOND RS, DA SILVA AGM AND CAMARGO PHC. 2018. Controlled synthesis of noble metal nanomaterials: Motivation, principles, and opportunities in nanocatalysis. An Acad Bras Cienc 90: 719-744.

GLEITER H. 2000. Nanostructured materials: basic concepts and microstructure. Acta Mater 48: 1-29.
GRZYBOWSKI BA AND HUCK WTS. 2016. The nanotechnology of life-inspired systems. Nat Nanotechnol 11: 585-592.

HE J, QI X, MIAO Y, WU H-L, HE N AND ZHU J-J. 2010. Application of smart nanostructures in medicine. Nanomedicine 5: 1129-1138.

HEATH J. 2003. NanoSystems biology. Mol Imaging Biol $5: 312-325$.

HUANG X, JAIN PK, EL-SAYED IH AND EL-SAYED MA. 2007. Gold nanoparticles: interesting optical properties and recent applications in cancer diagnostics and therapy. Nanomedicine 2: 681-693.

HUCZKOA. 2000. Template-based synthesis of nanomaterials. Appl Phys A Mater Sci Process 70: 365-376.

IHSSEN J, BRAUN A, FACCIO G, GAJDA-SCHRANTZ K AND THÖNY-MEYER L. 2014. Light harvesting proteins for solar fuel generation in bioengineered photoelectrochemical cells. Curr Protein Pept Sci 15: 374 384.

IVNITSKI D, BRANCH B, ATANASSOV P AND APBLETT C. 2006. Glucose oxidase anode for biofuel cell based on direct electron transfer. Electrochem Commun 8: 12041210.

JOSHI VK. 2016. Spintronics: A contemporary review of emerging electronics devices. Eng Sci Technol Int J 19: 1503-1513.

KUMAR A, NAUSHAD M, RANA A, INAMUDDIN, PREETI, SHARMA G, GHFAR AA, STADLER FJ AND KHAN MR. 2017. ZnSe-WO3 nano-hetero-assembly stacked on Gum ghatti for photo-degradative removal of Bisphenol A: Symbiose of adsorption and photocatalysis. Int J Biol Macromol 104: 1172-1184.

LAVAN DA, MCGUIRE T AND LANGER R. 2003. Smallscale systems for in vivo drug delivery. Nat Biotechnol 21: 1184-1191.

LOGOTHETIDIS S. 2012. Nanostructured Materials and Their Applications, NanoScience and Technology. Berlin, Heidelberg: Springer Berlin Heidelberg.

LOU H-Y, ZHAO W, ZENG Y AND CUI B. 2018. The Role of Membrane Curvature in Nanoscale Topography-Induced Intracellular Signaling. Acc Chem Res 51: 1046-1053.

LUZ RAS, PEREIRA AR, IOST RM AND CRESPILHO FN. 2018. Biofuel Cells. In: Souza, Flavio L. and Leite ER, editor. Nanoenergy. Cham: Springer International Publishing. p. 161-190.

LYKOURINOU V, CHEN Y, WANG X-S, MENG L, HOANG T, MING L-J, MUSSELMAN RL AND MA S. 2011. Immobilization of MP-11 into a Mesoporous Metal-Organic Framework, MP-11@mesoMOF: A New Platform for Enzymatic Catalysis. J Am Chem Soc 133: 10382-10385.

MA L, LI F, FANG T, ZHANG J AND WANG Q. 2015. Controlled Self-Assembly of Proteins into Discrete 
Nanoarchitectures Templated by Gold Nanoparticles via Monovalent Interfacial Engineering. ACS Appl Mater Interfaces 7: 11024-11031.

MAHMOUDI M, LYNCH I, EJTEHADI MR, MONOPOLI MP, BOMBELLI FB AND LAURENT S. 2011. ProteinNanoparticle Interactions: Opportunities and Challenges. Chem Rev 111: 5610-5637.

MAI BT, FERNANDES S, BALAKRISHNAN PB AND PELLEGRINO T. 2018. Nanosystems Based on Magnetic Nanoparticles and Thermo- or pH-Responsive Polymers: An Update and Future Perspectives. Acc Chem Res 51: 999-1013.

MAJUMDAR S, ŚLIWIŃSKI G AND GARCIA Y. 2017. Hybrid Organic-Inorganic Nanostructures for Spin Switching and Spintronic Applications. In: Hybrid Organic-Inorganic Interfaces. Weinheim, Germany: Wiley-VCH Verlag GmbH \& Co. KGaA. p. 301-353.

MIRANDA EGA ET AL. 2016. Effects of gold salt speciation and structure of human and bovine serum albumins on the synthesis and stability of gold nanostructures. Front Chem.

MONDAL PC, FONTANESI C, WALDECK DH AND NAAMAN R. 2015. Field and chirality effects on electrochemical charge transfer rates: Spin dependent electrochemistry. ACS Nano 9: 3377-3384.

MONNIER CA, BURNAND D, ROTHEN-RUTISHAUSER B, LATTUADA M AND PETRI-FINK A. 2014. Magnetoliposomes: opportunities and challenges. Eur J Nanomedicine 6: 201-215.

NIU W, ZHANG L AND XU G. 2013. Seed-mediated growth of noble metal nanocrystals: crystal growth and shape control. Nanoscale 5: 3172.

OLYVEIRA GM, IOST RM, LUZ RAS AND CRESPILHO FN. 2013. Biofuel Cells: Bioelectrochemistry Applied to the Generation of Green Electricity. In: Nanoenergy. Berlin, Heidelberg: Springer Berlin Heidelberg, p. 101123.

PAN H ET AL. 2013. Programmable nanoparticle functionalization for in vivo targeting. FASEB J 27: 255 264.

PARAMESWARAN R AND TIAN B. 2018. Rational Design of Semiconductor Nanostructures for Functional Subcellular Interfaces. Acc Chem Res 51: 1014-1022.

PEREIRA A, DE SOUZA J, GONÇALVES A, PAGNONCELLI K, CRESPILHO F, PEREIRA AR, SOUZA JCP DE, GONÇALVES AD, PAGNONCELLI KC AND CRESPILHO FN. 2017. Bioelectrooxidation of Ethanol Using NAD-Dependent Alcohol Dehydrogenase on Oxidized Flexible Carbon Fiber Arrays. J Braz Chem Soc 28: 1698-1707.

PEREIRA AR, IOST RM, MARTINS MVA, YOKOMIZO CH, DA SILVA WC, NANTES IL AND CRESPILHO FN. 2011. Molecular interactions and structure of a supramolecular arrangement of glucose oxidase and palladium nanoparticles. Phys Chem Chem Phys.

POLTE J. 2015. Fundamental growth principles of colloidal metal nanoparticles - a new perspective. CrystEngComm 17: 6809-6830.

PURCHASE RL AND DE GROOT HJM. 2015. Biosolar cells: global artificial photosynthesis needs responsive matrices with quantum coherent kinetic control for high yield. Interface Focus 5: 20150014.

RAO CNR, CHINTAMANI NR, MÜLLER A AND CHEETHAM AK. 2004a. John Wiley \& Sons. The chemistry of nanomaterials : synthesis, properties and applications in 2 volumes. Wiley-VCH.

RAO CNR, CHINTAMANI NR, MÜLLER A AND CHEETHAM AK. 2004b. John Wiley \& Sons. The chemistry of nanomaterials : synthesis, properties and applications in 2 volumes. Wiley-VCH.

RHYNER MN, SMITH AM, GAO X, MAO H, YANG L AND NIE S. 2006. Quantum dots and multifunctional nanoparticles: new contrast agents for tumor imaging. Nanomedicine 1: 209-217.

RODARY G, SANDER D, LIU H, ZHAO H, NIEBERGALL L, STEPANYUK VS, BRUNO P AND KIRSCHNER J. 2007. Quantization of the electron wave vector in nanostructures: Counting <math display="inline" $>$ $<$ mi $>$ k $</$ mi $><$ math $>$-states. Phys Rev B 75: 233412.

RODUNER E. 2006. Size matters: Why nanomaterials are different. Chem Soc Rev 35: 583-592.

SALATA O. 2004. Applications of nanoparticles in biology and medicine. J Nanobiotechnology 2: 3 .

SANHAI WR, SAKAMOTO JH, CANADY R AND FERRARI M. 2008. Seven challenges for nanomedicine. Nat Nanotechnol 3: 242-244.

SANTOS GP, MELO AFAA AND CRESPILHO FN. 2014. Magnetically controlled single-nanoparticle detection via particle-electrode collisions. Phys Chem Chem Phys 16: 8012-8018.

SEEHRA MS. 2017. Nanostructured Materials - Fabrication to Applications. InTech.

SIRIWARDANA K, WANG A, GADOGBE M, COLLIER WE, FITZKEE NC AND ZHANG D. 2015. Studying the Effects of Cysteine Residues on Protein Interactions with Silver Nanoparticles. J Phys Chem C Nanomater Interfaces 119: 2910-2916.

SITTI M. 2018. Miniature soft robots — road to the clinic. Nat Rev Mater 3: 74-75.

SIVULA K, LE FORMAL F AND GRÄTZEL M. 2011. Solar Water Splitting: Progress Using Hematite $(\alpha-\mathrm{Fe} 2 \mathrm{O} 3)$ Photoelectrodes. ChemSusChem 4: 432-449.

SOMASUNDARAN P, CHIN M, LATOSIEWICZ UT, TULLER HL, BARBIELLINI B AND RENUGOPALAKRISHNAN V. 2011. Nanoscience and 
Engineering for Robust Biosolar Cells. Bionanotechnol II Glob Prospect. 427-454.

SPICER CD AND DAVIS BG. 2014. Selective chemical protein modification. Nat Commun 5: 4740.

TOFANELLO A, MIRANDA ÉGA, DIAS IWR, LANFREDI AJC, ARANTES JT, JULIANO MA AND NANTES IL. 2016. PH-Dependent Synthesis of Anisotropic Gold Nanostructures by Bioinspired Cysteine-Containing Peptides. ACS Omega 1: 424-434.

UCHIDA M, KLEM MT, ALLEN M, SUCI P, FLENNIKEN M, GILLITZER E, VARPNESS Z, LIEPOLD LO, YOUNG M AND DOUGLAS T. 2007. Biological Containers: Protein Cages as Multifunctional Nanoplatforms. Adv Mater 19: 1025-1042.

WREST S. 2017. Funding China's civil society - Tax incentives, donation law, and the role of foreign charities,
China Business Review. Cambridge: Royal Society of Chemistry.

XIA Y, XIONG Y, LIM B AND SKRABALAK SE. 2009. Shape-Controlled Synthesis of Metal Nanocrystals: Simple Chemistry Meets Complex Physics? Angew Chemie Int Ed 48: 60-103.

ZANG L. 2011. Energy efficiency and renewable energy through nanotechnology. Springer.

ZHANG A AND LIEBER CM. 2016. Nano-Bioelectronics. Chem Rev 116: 215-257.

ZHANG W, BANERJEE-GHOSH K, TASSINARI F AND NAAMAN R. 2018. Enhanced Electrochemical Water Splitting with Chiral Molecule-Coated $\mathrm{Fe}_{3} \mathrm{O}_{4}$ Nanoparticles. ACS Energy Lett 3: 2308-2313. 